\title{
Nondestructive Post-fire Damage Assessment of Structural Steel Members Using Leeb Harness Method
}

\author{
Dianzhong Liu, Xinyi Liu and Wugang Wang, School of Civil Engineering, Jilin \\ Jianzhu University, No. 5088 Xincheng Avenue, Jingyue Economic \\ Development Zone, Changchun 130118 Jilin, People's Republic of China
} Feng Fu $\mathbb{D}^{*}$, Department of Civil Engineering, School of Mathematics, Computer Science and Engineering, City, University of London, Northampton Square, London EC1V OHB, UK

Received: 27 July 2019/Accepted: 16 January 2020

\begin{abstract}
Assessment of steel damage is one of the key methods in retrofitting and reconstruction of the steel structures after fire. The traditional assessment method is to cut the samples from the steel members and check the levels of damage. This method will damage the structural members and the process is time consuming. In this paper, a quick, simple and efficient nondestructive detection method to measure the strength of steel after fire is developed using so called Leeb hardness method by means of establishment the relationship between the residual strength of steel members after fire and the Leeb hardness, the post-fire steel strength can be fast determined without damage to the structural members. In this paper, in total 120 Chinese $\mathrm{H}$-shaped steel sections were selected for testing the Leeb hardness after fire. The influence of the parameters such as the duration of the fire exposure, cooling mode, steel grade, stress state and location of the Leeb hardness test on the test results was investigated. The relationship between the steel Leeb hardness and the parameters were developed. In addition, regression functions between the residual strength of steel members after fire and the Leeb hardness was established based on these test results which can accurate predict the residual strength of the steel members after fire, providing the engineers a new fast assessment method for the residual strength of the steel after fire.
\end{abstract}

Keywords: Post fire damage assessment, Leeb hardness, Steel strength, Cooling mode, Fire exposure

\section{Introduction}

Some steel structures can be repaired and reconstructed after the fire has been extinguished. Post-fire assessment facilitates the decision making on the possibility of further operation of the facility after fire accident. In order to determine the residual capacity of structural steel members, it is necessary to test and assess the

\footnotetext{
* Correspondence should be addressed to: Feng Fu, E-mail: cenffu@yahoo.co.uk
} 
structural steel members before repairing [1-3]. As part of this process, the strength of the steel is an important parameter. Being able to know the residual strength of the steel, it can accurately determine the retrofitting methods for the whole structure which plays a significance role for the restoration of the designed bearing capacity and the serviceability of the steel structure after the fire disaster.

The method for testing the residual strength of steel after fire includes on-site coupon tensile testing, chemical composition analysis method and surface hardness method [4-10] (including Brinell hardness method, Rockwell hardness method, Victoria hardness method, Leeb hardness method), etc. The most accurate one is on-site coupon tensile testing. This method is to cut the coupon from the structural members of the building and perform tensile testing. However, this method causes different degrees of damage to the structure, which are not suitable to post-fire restoration work. The chemical composition analysis method also needs on-site sampling and the process is tedious.

At present, there is little research on the non-destructive method for testing of steel strength after the fire. Some work of $[11,12]$ provide non-destructive method for testing the concrete strength after fire. Little work has been done for steel members.

Leeb Hardness testing is a non-destructive method for testing the strength of the steel members. This method is easy, flexible and can be tested directly on the structural members without cutting the coupons. It is invented by Dietamar Leeb in 1975. The benefit of using Leeb method is that as it shown in Fig. 5, the drop hammer is small and it is easy to maneuver, especially in narrow place where access may become a problem. The whole test process is fast. The disadvantage of this method is that the surface needs to be processed first.

The method of the Leeb hardness testing is to drop certain weight of object through a tube to the surface of the specimens and test the impact velocity of object and the velocity of the object at $1 \mathrm{~mm}$ distance of the surface when it bounces back. The formula is show as follows:

$$
H L=1000 \frac{V_{R}}{V_{A}}
$$

where

$H L$ - is the Leeb hardness,

$V_{R}$ - is the bounce back velocity of the object,

$V_{A}$-is the impact velocity of the object.

In this paper, the conventional Chinese $\mathrm{H}$-shaped steel sections were used for fire testing. After fire test, the Leeb hardness method is used to measure the hardness of $\mathrm{H}$-shaped sections after fire. The influence of different parameters such as duration of fire exposure, steel grade, stress state and locations of different parts on the Leeb hardness was studied. In addition, regression functions between the residual strength of steel members after fire and the Leeb hardness was established based on these test results which provides the engineers a new fast assessment method for the residual strength of the steel after fire. 


\section{Experimental Program}

\subsection{Fire Test Set $U p$}

The fire test is conducted in an electric heating furnace, as shown in Fig. 1, and schematic diagram of test rigs is shown in Fig. 2. The test rigs shown in Fig. 2 can apply axial load simultaneously during the heating of the specimen in the furnace. The dimension of the furnace is $\phi 500 \times 600 \mathrm{~mm}$, with interior dimension of $\phi 280 \times 400 \mathrm{~mm}$.

\subsection{Test specimens}

In order to develop this new post-fire assessment method, Chinese steel section $\mathrm{H} 100 \times 100 \times 6 \times 8$ was used for fire tests and subsequent Leeb hardness tests. The steel grades were Q235, Q345 and Q390 respectively with the member length of $500 \mathrm{~mm}$. Among them, Q390 steel sections was cold welded by three steel plates and the remaining sections were hot-rolled sections. 108 specimens were tested after fire exposure with the other 12 specimens was tested at ambient temperature for comparison, altogether 120 specimens. The numbers of the specimens are given in Table 1 .

\subsection{Parameters Investigated During the Tests}

In order to completely understand the response of the structure after fire, the factors such as the duration of fire exposure, cooling mode, steel grade, stress state and different parts of $\mathrm{H}$-beam were considered in the fire tests. The tests focused on the effect of the selected parameters on the mechanical properties of steel components after fires:

1. The fire temperatures during the tests are $100^{\circ} \mathrm{C}, 200^{\circ} \mathrm{C}, 300^{\circ} \mathrm{C}, 400^{\circ} \mathrm{C}, 500^{\circ} \mathrm{C}$ and $600^{\circ} \mathrm{C}$ respectively. This is because that, when the temperature reaches $600^{\circ} \mathrm{C}$, according the characteristic of the steel material, the yield strength of the steel has degradation to $60 \%$ of its original strength. The steel members will lose almost all the strength and rigidity the structural steel member will experience serious buckling, deformation and even complete damage. It is not suitable to take any load. However, if the load taken by the fire affected member is small, the steel structure can still survive. However, the cost won't allow us to consider all the possibility such as different load ratio, so in the tests, all the specimens were heated up to $600^{\circ} \mathrm{C}$ and stopped.

2. Two types of cooling mode were used after fire testing: water cooling and natural cooling.

3. Stress state and non-stress stage are both investigated.

\subsection{Test Procedure and Parameters}

\subsubsection{Fire Test}

2.4.1.1. The Fire Temperature and Furnace Temperatures Range The purpose of this experiment is to investigate the mechanical properties of steel components 


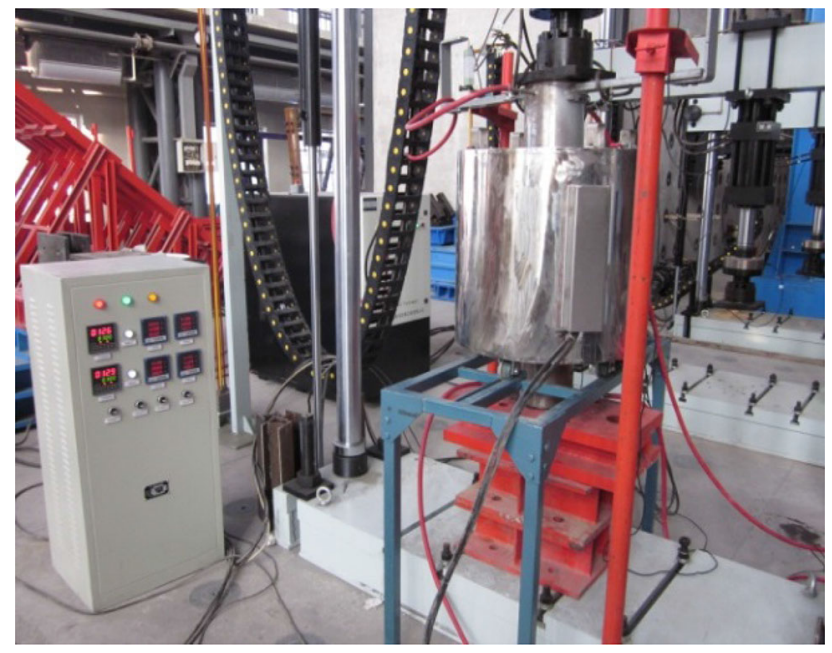

Figure 1. Electric heating furnace.

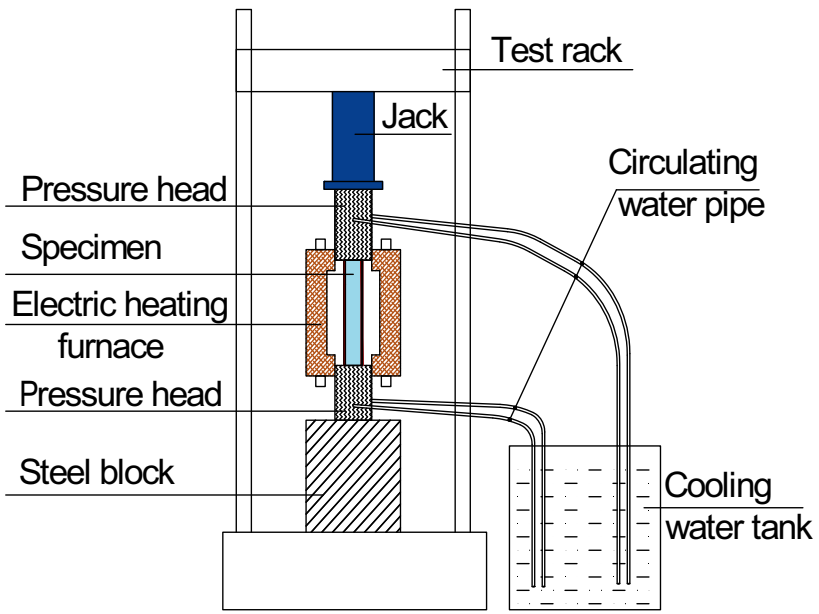

\section{Figure 2. Schematic diagram of test rigs.}

after the fire [13-17]. As it has been explained, maximum temperature of $600^{\circ} \mathrm{C}$ (as it shown in Fig. 3) was used in the fire tests. Figure 3 shows the actual furnace temperature during the test.

2.4.1.2. Heating Rate and Duration of Fire Exposure The heating rate is shown Fig. 3. When the furnace reached each control temperature $100^{\circ} \mathrm{C}, 200^{\circ} \mathrm{C}, 300^{\circ} \mathrm{C}$, $400^{\circ} \mathrm{C}, 500^{\circ} \mathrm{C}$ and $600^{\circ} \mathrm{C}$ respectively, the temperature was kept constant for a certain time before raising further. According to the relevant research [18-25] and the 


\section{Table 1}

Specimen Details

\begin{tabular}{|c|c|c|c|c|c|c|c|c|}
\hline \multirow{2}{*}{$\begin{array}{l}\text { Steel } \\
\text { grade }\end{array}$} & \multirow[b]{2}{*}{ Cooling mode } & \multirow{2}{*}{$\begin{array}{l}\text { Fire exposure time } \\
(\mathrm{min})\end{array}$} & \multicolumn{6}{|c|}{ Temperature $\left({ }^{\circ} \mathrm{C}\right)$} \\
\hline & & & 100 & 200 & 300 & 400 & 500 & 600 \\
\hline \multirow[t]{6}{*}{ Q235 } & \multirow[t]{3}{*}{ Water cooling } & 5 & $\mathrm{AW}_{1}^{5}$ & $\mathrm{AW}_{2}^{5}$ & $\mathrm{AW}_{3}^{5}$ & $\mathrm{AW}_{4}^{5}$ & $\mathrm{AW}_{5}^{5}$ & $\mathrm{AW}_{6}^{5}$ \\
\hline & & 10 & $\mathrm{AW}_{1}^{10}$ & $\mathrm{AW}_{2}^{10}$ & $\mathrm{AW}_{3}^{10}$ & $\mathrm{AW}_{4}^{\mathrm{i} 0}$ & $\mathrm{AW}_{5}^{10}$ & $\mathrm{AW}_{6}^{\mathrm{ll}}$ \\
\hline & & 15 & $\mathrm{AW}_{1}^{15}$ & $\mathrm{AW}_{2}^{15}$ & $\mathrm{AW}_{3}^{15}$ & $\mathrm{AW}_{4}^{15}$ & $\mathrm{AW}_{5}^{15}$ & $\mathrm{AW}_{6}^{1}$ \\
\hline & \multirow{3}{*}{$\begin{array}{l}\text { Natural cool- } \\
\text { ing }\end{array}$} & 5 & $\mathrm{AN}_{1}^{5}$ & $\mathrm{AN}_{2}^{5}$ & $\mathrm{AN}_{3}^{5}$ & $\mathrm{AN}_{4}^{5^{4}}$ & $\mathrm{AN}_{5}^{5}$ & $\mathrm{AN}_{6}^{5}$ \\
\hline & & 10 & $\mathrm{AN}_{1}^{\mathrm{i} 0}$ & $\mathrm{AN}_{2}^{\mathrm{I} 0}$ & $\mathrm{AN}_{3}^{10}$ & $\mathrm{AN}_{4}^{\mathrm{i} 0}$ & $\mathrm{AN}_{5}^{10}$ & $\mathrm{AN}_{6}^{10}$ \\
\hline & & 15 & $\mathrm{AN}_{1}^{15}$ & $\mathrm{AN}_{2}^{15}$ & $\mathrm{AN}_{3}^{15}$ & $\mathrm{AN}_{4}^{15}$ & $\mathrm{AN}_{5}^{15}$ & $\mathrm{AN}_{6}^{15}$ \\
\hline \multirow[t]{6}{*}{ Q345 } & \multirow[t]{3}{*}{ Water cooling } & 5 & $\mathrm{BW}_{1}^{5}$ & $\mathrm{BW}_{2}^{5}$ & $\mathrm{BW}_{3}^{5}$ & $\mathrm{BW}_{4}^{5}$ & $\mathrm{BW}_{5}^{5}$ & $\mathrm{BW}_{6}^{5}$ \\
\hline & & 10 & $\mathrm{BW}_{1}^{10}$ & $\mathrm{BW}_{2}^{\mathrm{10}}$ & $\mathrm{BW}_{3}^{10}$ & $\mathrm{BW}_{4}^{10}$ & $\mathrm{BW}_{5}^{10}$ & $\mathrm{BW}_{6}^{10}$ \\
\hline & & 15 & $\mathrm{BW}_{1}^{15}$ & $\mathrm{BW}_{2}^{15}$ & $\mathrm{BW}_{3}^{15}$ & $\mathrm{BW}_{4}^{15}$ & $\mathrm{BW}_{5}^{15}$ & $\mathrm{BW}_{6}^{15}$ \\
\hline & \multirow{3}{*}{$\begin{array}{l}\text { Natural cool- } \\
\text { ing }\end{array}$} & 5 & $\mathrm{BN}_{1}^{5}$ & $\mathrm{BN}_{2}^{5}$ & $\mathrm{BN}_{3}^{5}$ & $\mathrm{BN}_{4}^{5}$ & $\mathrm{BN}_{5}^{5}$ & $\mathrm{BN}_{6}^{5}$ \\
\hline & & 10 & $\mathrm{BN}_{1}^{10}$ & $\mathrm{BN}_{2}^{10}$ & $\mathrm{BN}_{3}^{10}$ & $\mathrm{BN}_{4}^{10}$ & $\mathrm{BN}_{5}^{10}$ & $\mathrm{BN}_{6}^{10}$ \\
\hline & & 15 & $\mathrm{BN}_{1}^{15}$ & $\mathrm{BN}_{2}^{15}$ & $\mathrm{BN}_{3}^{15}$ & $\mathrm{BN}_{4}^{15}$ & $\mathrm{BN}_{5}^{15}$ & $\mathrm{BN}_{6}^{15}$ \\
\hline \multirow{6}{*}{ Q390 } & \multirow[t]{3}{*}{ Water cooling } & 5 & $\mathrm{CW}_{1}^{5}$ & $\mathrm{CW}_{2}^{5}$ & $\mathrm{CW}_{3}^{5}$ & $\mathrm{CW}_{4}^{5}$ & $\mathrm{CW}_{5}^{5}$ & $\mathrm{CW}_{6}^{5}$ \\
\hline & & 10 & $\mathrm{CW}_{1}^{\mathrm{i} 0}$ & $\mathrm{CW}_{2}^{10}$ & $\mathrm{CW}_{3}^{10}$ & $\mathrm{CW}_{4}^{\mathrm{I} 0}$ & $\mathrm{CW}_{5}^{10}$ & $\mathrm{CW}_{6}^{1 \mathrm{l}}$ \\
\hline & & 15 & $\mathrm{CW}_{1}^{15}$ & $\mathrm{CW}_{2}^{15}$ & $\mathrm{CW}_{3}^{15}$ & $\mathrm{CW}_{4}^{15}$ & $\mathrm{CW}_{5}^{15}$ & $\mathrm{CW}_{6}^{15}$ \\
\hline & \multirow{3}{*}{$\begin{array}{l}\text { Natural cool- } \\
\text { ing }\end{array}$} & 5 & $\mathrm{CN}_{1}^{5}$ & $\mathrm{CN}_{2}^{5}$ & $\mathrm{CN}_{3}^{5}$ & $\mathrm{CN}_{4}^{5}$ & $\mathrm{CN}_{5}^{5}$ & $\mathrm{CN}_{6}^{5}$ \\
\hline & & 10 & $\mathrm{CN}_{1}^{10}$ & $\mathrm{CN}_{2}^{10}$ & $\mathrm{CN}_{3}^{10}$ & $\mathrm{CN}_{4}^{\mathrm{I} 0}$ & $\mathrm{CN}_{5}^{10}$ & $\mathrm{CN}_{6}^{10}$ \\
\hline & & 15 & $\mathrm{CN}_{1}^{15}$ & $\mathrm{CN}_{2}^{15}$ & $\mathrm{CN}_{3}^{15}$ & $\mathrm{CN}_{4}^{15}$ & $\mathrm{CN}_{5}^{15}$ & $\mathrm{CN}_{6}^{15}$ \\
\hline
\end{tabular}

A, B, C respectively represents Q235, Q345 and Q390 steel grades; W and N respectively represent water cooling mode and natural cooling mode, the subscripts $1-6$ respectively represents the temperature of $100^{\circ} \mathrm{C}$ to $600^{\circ} \mathrm{C}$, and the superscripts 5,10 and 15 respectively represent the fire exposure time at the specific test temperature

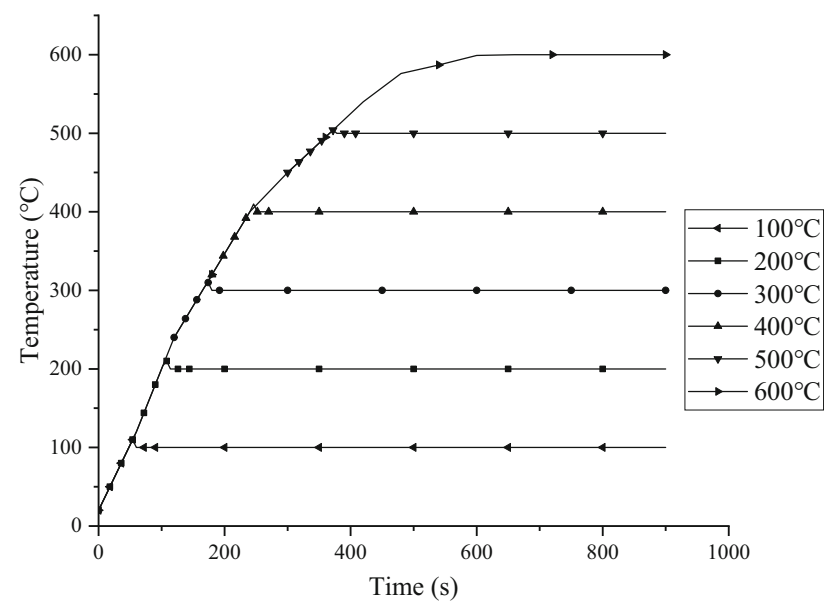

\section{Figure 3. Time temperature curve in furnace for each test.}

observation of structure fire tests, the strength and rigidity of bare steel members will start to lose after exposure to fire temperature for $20 \mathrm{~min}$. The purpose of this experiment is to provide experimental and theoretical basis for the reinforcement 
and repair of steel structure after the fire. Therefore, the durations of constant fire exposure of the test are $5 \mathrm{~min}, 10 \mathrm{~min}$ and $15 \mathrm{~min}$ respectively.

2.4.1.3. Temperature Control The thermal couples are evenly placed inside the furnace along the height to monitor the temperature of the furnace. The precision for each control temperature is $\pm 1^{\circ} \mathrm{C}$. It is also presume that after fire exposure, the temperature of steel structural is the same as the temperature inside the furnace.

2.4.2. Cooling Process and Parameters Two cooling modes are used, natural cooling and water cooling.

1. The water cooling is to use water with ambient temperature to pour directly on the specimens after they were taken out from the furnace. During the cooling stage, an infrared thermometer is used to test the surface temperature of the specimen, the cooling stopped when the surface temperature dropped to around $20^{\circ} \mathrm{C}$.

2. In natural cooling, after the specimens were taken out from the furnace, it would be placed on the ground for $24 \mathrm{~h}$. Then the surface temperature of the specimen was tested using an infrared thermometer to make sure the surface temperature dropped to around $20^{\circ} \mathrm{C}$ before Leeb test.

2.4.3. Different Stress State The measurement of Leeb hardness under different stress states: stress state and non-stress state. As it shown in Fig. 4a, the stress is almost 0 . As it shown in Fig. 4b, the load is applied through a hydraulic jack, the load is applied to $70 \%$ of the design load of the steel structural member. So, the stress level for the different grade of specimens are $146 \mathrm{~N} / \mathrm{mm}^{2}$ (Q235), $207 \mathrm{~N} /$ $\mathrm{mm}^{2}$ (Q345), $232 \mathrm{~N} / \mathrm{mm}^{2}$ (Q390) respectively.

\subsection{Post-fire Leeb Hardness Tests}

Both the stress and non-stress states are considered in the hardness test scheme [23-26], different thickness of steel flange and web and different location of the steel beam are considered for testing. In term of stress state, the load applied to the specimen in the high-temperature test furnace can better reflect the actual state of the steel structural members after the fire and at the scene of the fire.

The tests are conducted under the Chinese standard [27, 28]. A digital Leeb hardness tester TIME5351 was used (Fig. 5). As it shown in Fig. 6, the specimens were first grinded into three separate smooth zones $(30 \times 60 \mathrm{~mm})$ for the test. The surface roughness was first assessed as it shown in Fig. 7. 9 tests were done for each smooth zone, the average the 9 readings after remove the maximum and minimum value was used.

As it shown in Fig. 8, the measurement of Leeb hardness is performed in both the stress and non-stress states. In the non-stress state, in order to prevent partial 


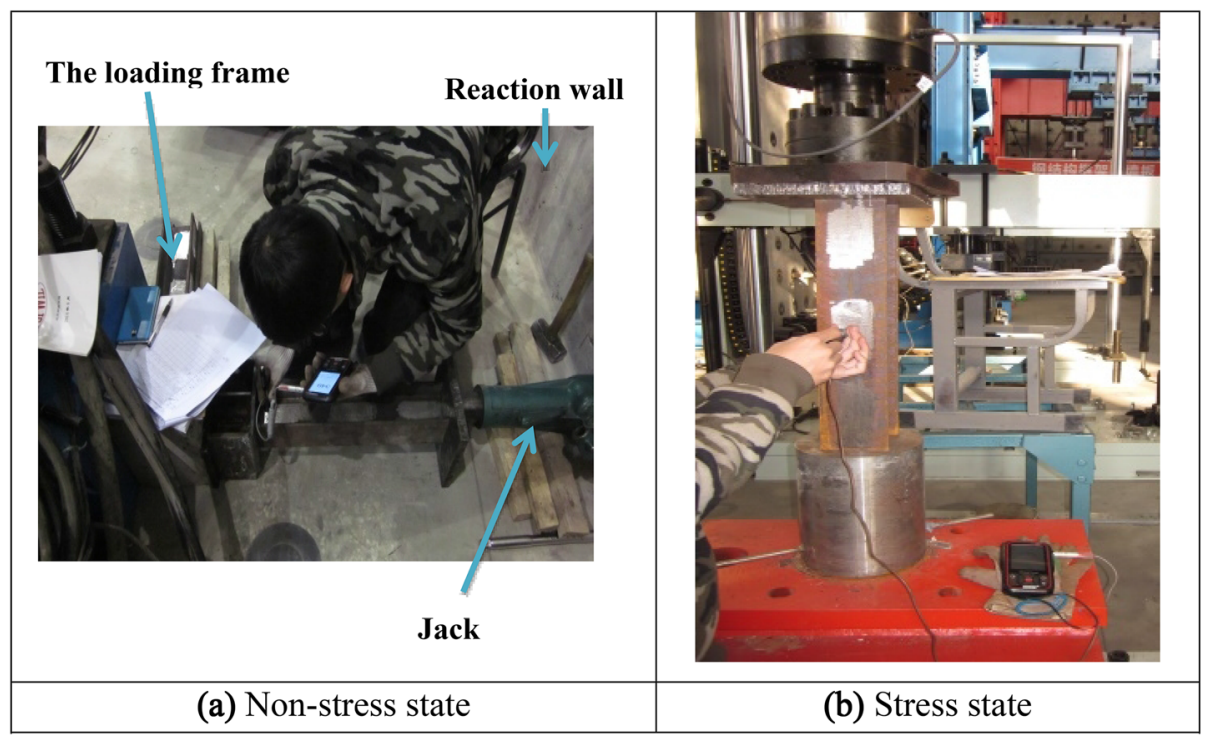

Figure 4. The measurement of Leeb hardness under different stress state.

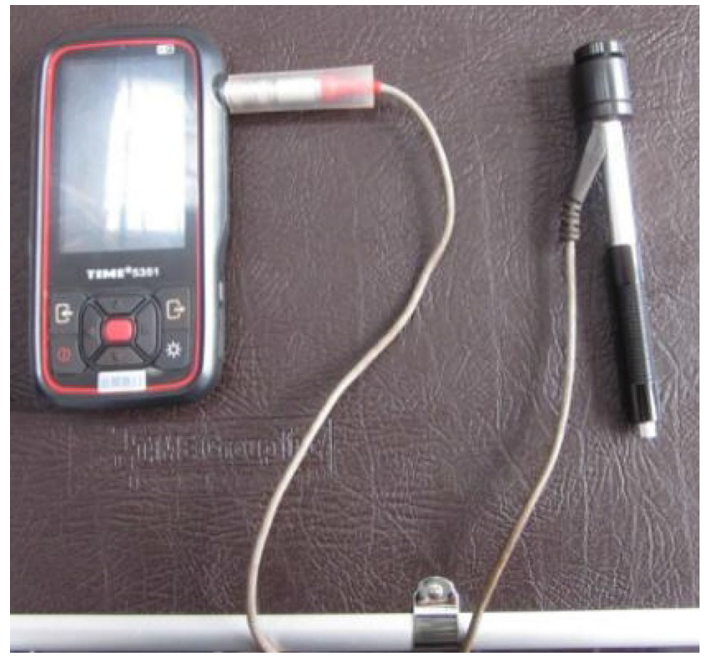

\section{Figure 5. TIME5351 Leeb hardness tester.}

energy loss caused by displacement or vibration of the specimen during the impact, this test uses a reaction frame, a reaction wall and a mechanical jack to restraint the specimens, as it shown in Fig. 8a, to ensure no shaking and no movement would occur during the Leeb hardness test. 


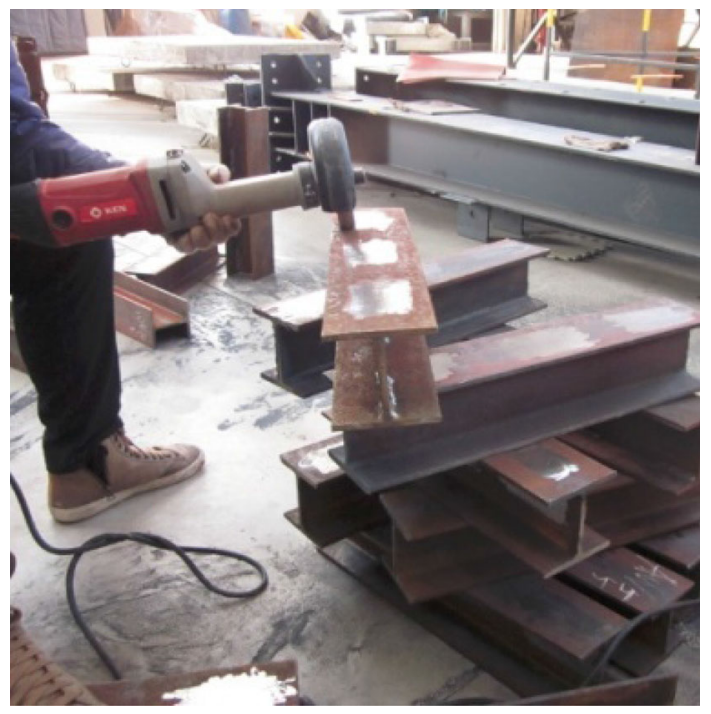

\section{Figure 6. Grinding zone.}

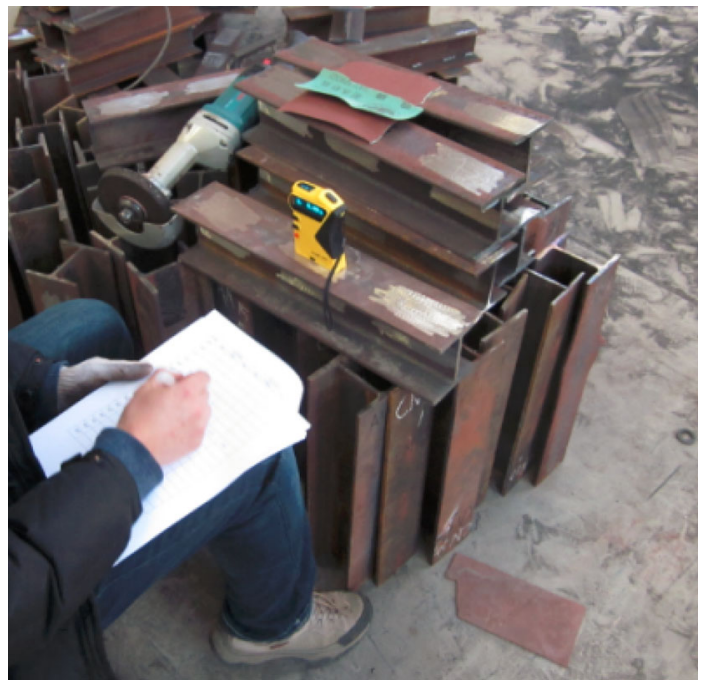

\section{Figure 7. Roughness assessment.}

The stress state is to exert pressure to the specimens after the cooling from fire exposure, as it shown in Fig. 8b. The load is applied as $70 \%$ of the residual bearing capacity of the test specimen through the hydraulic loading system, and the Leeb hardness of the specimens is tested under the pressure. 


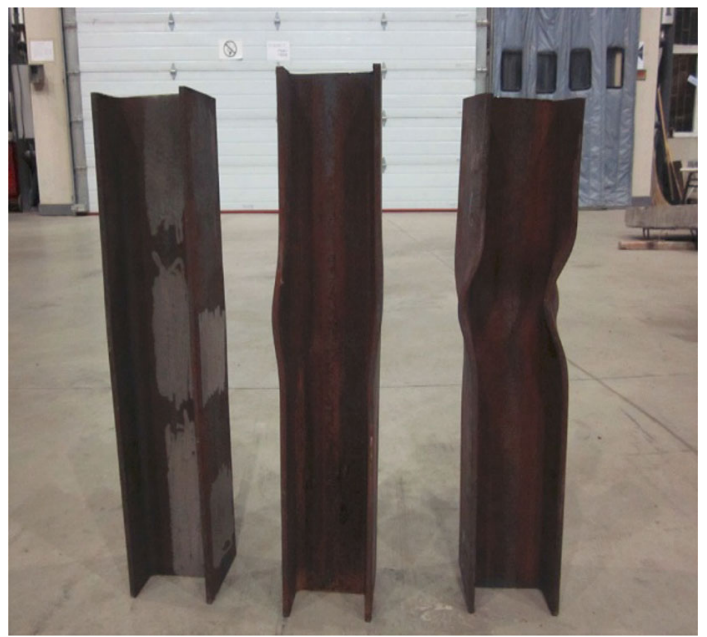

Figure 8. Buckling deformation at temperatures of $400^{\circ} \mathrm{C}$ to $600^{\circ} \mathrm{C}$.

\section{Test Results Analysis}

For most of the specimens, they were loaded up to $70 \%$ of their design load. The test results show that when fire tests were carried out at the temperature of $100^{\circ} \mathrm{C}$ to $300^{\circ} \mathrm{C}$, the axial capacity of the specimens was basically unaffected, and there was no buckling observed. The axial capacity of the specimen decreased with various degrees of buckling deformation occurred when the temperature increased to the range of $400^{\circ} \mathrm{C}$ to $600^{\circ} \mathrm{C}$, which results in a small fluctuation in the loading actuator is observed [26]. The different degrees of buckling deformation at temperatures of $400^{\circ} \mathrm{C}$ to $600^{\circ} \mathrm{C}$ are shown in Fig. 6. Some specimens were loaded up to $50 \%$ of their design load, it is found that, buckling was not observed [29].

\subsection{Effect of Cooling Mode and Fire Exposure Duration of Fire Exposure on Leeb Hardness}

After the fire tests, Leeb hardness test of Q235 specimens under water cooling and natural cooling methods are both performed. The effect of different cooling modes on Leeb hardness are considered with the other factors such as fire temperature, stress state and detection portion are constant. Figure 9 shows the relationship between the fire exposure time and Leeb hardness at the temperature of $100^{\circ} \mathrm{C}$, $200^{\circ} \mathrm{C}, 300^{\circ} \mathrm{C}, 400^{\circ} \mathrm{C}, 500^{\circ} \mathrm{C}$ and $600^{\circ} \mathrm{C}$. Leeb hardness of both cooling modes shows a slight growth trend with the increase of fire exposure time. The corresponding Leeb hardness scale increased by about 3 HLD when the fire exposure duration of fire exposure changed from $5 \mathrm{~min}$ to $15 \mathrm{~min}$, the effect of fire exposure duration of fire exposure is very limited. When fire exposure duration is the same, the value Leeb hardness under water cooling method is about 35 HLD higher than that of natural cooling. When the specimen is suddenly cooled by water at high temperature, it is equivalent to a quenching process for the steel, 
which results in its surface hardness increased. Therefore, the cooling method has a great influence on the Leeb hardness. Apart from this, the cooling process is determined by the way of putting off the fire, therefore, it is an important factor need to be considered.

The water-cooling method is to pour Watering at high temperature, is equivalent to a quenching process for steel. When the temperature reaches $400^{\circ} \mathrm{C}$ or higher, the cementite of the internal structure becomes pearlite, the yield strength increase, and the ductility deteriorates increase. The natural cooling method (air cooling) is equivalent to a normalizing process for steel. The internal structure of the grain becomes finer, the mechanical properties are improved, and the hardness is slightly lowered [30].

\subsection{Effect of Steel Strength Grade on Leeb Hardness}

As it shown in Figs. 10 and 11, the relationship between the hardness and the steel strength grades at different fire exposure under water cooling is analyzed. In the same conditions of cooling mode and fire exposure time, no matter what kind of steel strength grade of the specimen its hardness is increased with the increase of the fire temperature. Average Leeb hardness increases by 12 HLD when the fire temperature raises from $100^{\circ} \mathrm{C}$ to $600^{\circ} \mathrm{C}$, so the fire temperature has a certain influence on the Leeb hardness. In the same conditions of cooling mode and fire exposure time, Leeb hardness increases greatly with the increase of steel strength grade. In the case of watering cooling, the average Leeb hardness of Q345 specimen is about 28 HLD higher than that of Q235 specimen, the hardness of Q390 specimen is about 43 HLD higher than that of Q345 specimen. The results show that the Leeb hardness increases linearly with the increase of steel strength. The steel strength grade is the main factor affecting the Leeb hardness.

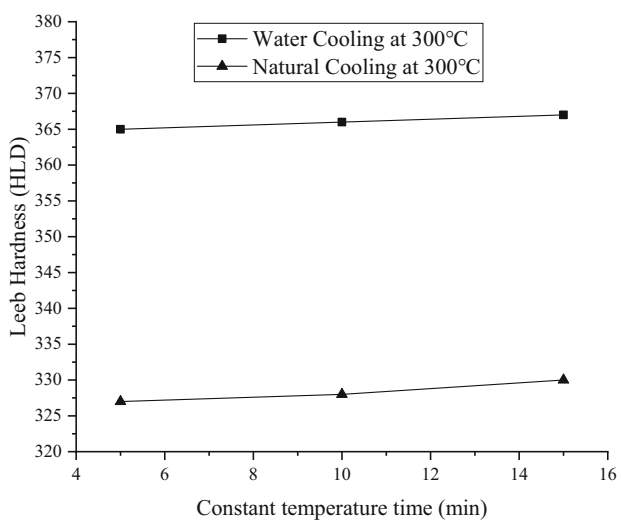

(a) At $300^{\circ} \mathrm{C}$

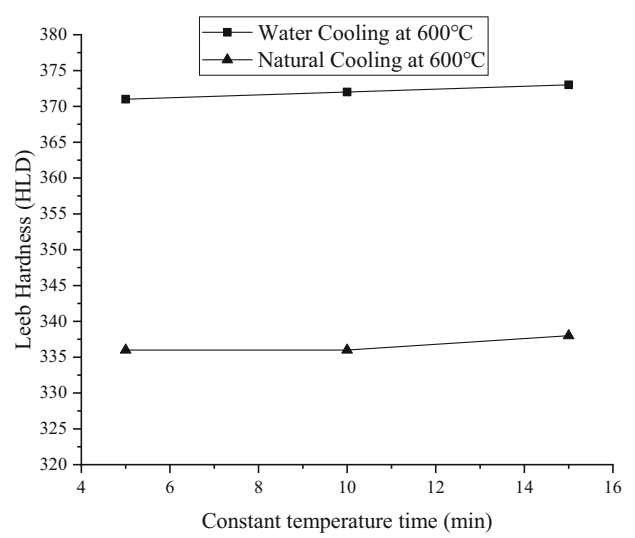

(b) At $600^{\circ} \mathrm{C}$

Figure 9. Influence of cooling mode on Leeb hardness. 


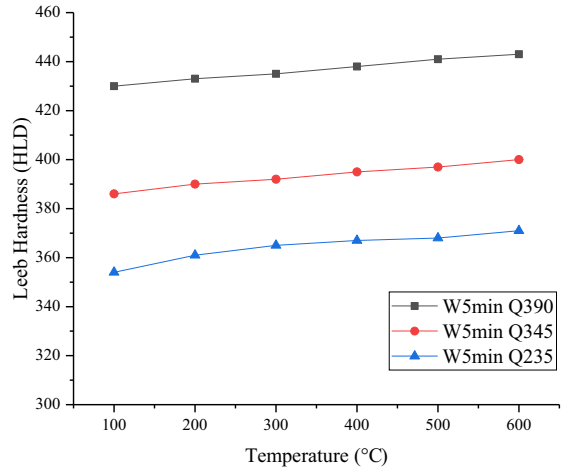

(a) Fire exposure of 5mins

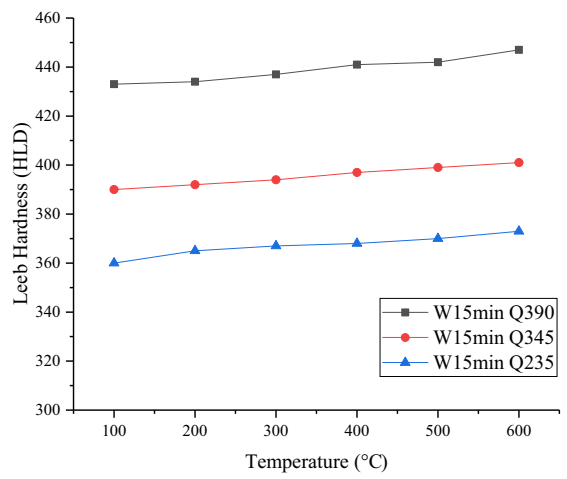

(c) Fire exposure of $15 \mathrm{mins}$

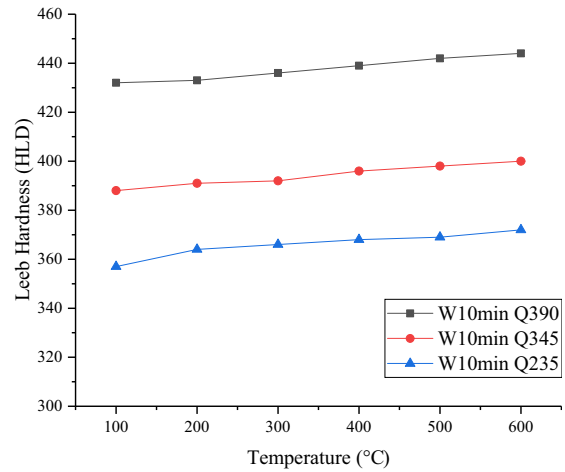

(b) Fire exposure of 10mins

\section{Figure 10. Relation bełween Leeb hardness steel grades under water cooling.}

\subsection{Effect of Stress State on Leeb Hardness}

The Leeb hardness of Q235 specimens of stressed and non-stress state with natural cooling increases slightly with the increase of fire temperature when the fire exposure duration is the same. At the same fire temperature, the Leeb hardness of the stress state is higher than that of the non-stress state, and the general variation range is within $5 \mathrm{HLD}$. Only when the fire temperature is between $200^{\circ} \mathrm{C}$ and $300^{\circ} \mathrm{C}$, the difference between the two reaches about 8 HLD. It can be seen that the influence of the stress state on the hardness value is not evident.

When the fire exposure duration is the same with water cooling, Leeb hardness of the stress state is close to that of the non-stress state, and the general variation range is about $3 \mathrm{HLD}$. When the fire temperature is $600^{\circ} \mathrm{C}$, the difference in hardness between the two reaches 10 HLD, and the abnormal value appears. 


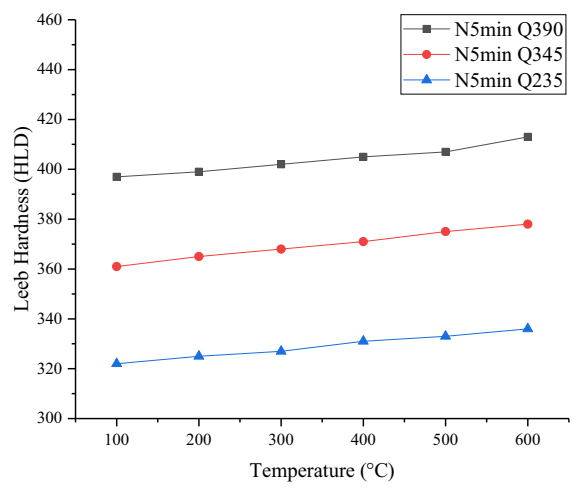

(a) Fire exposure of 5mins

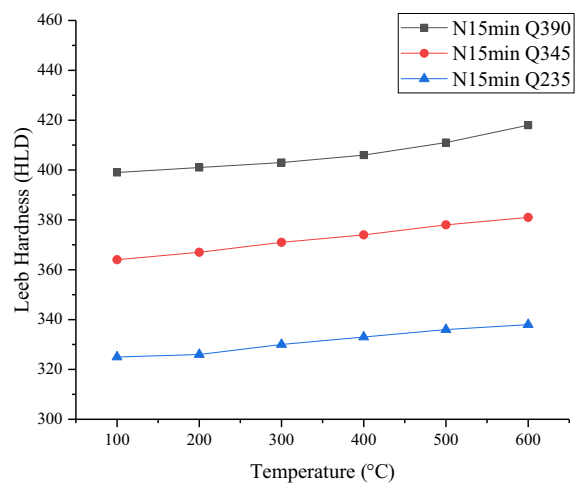

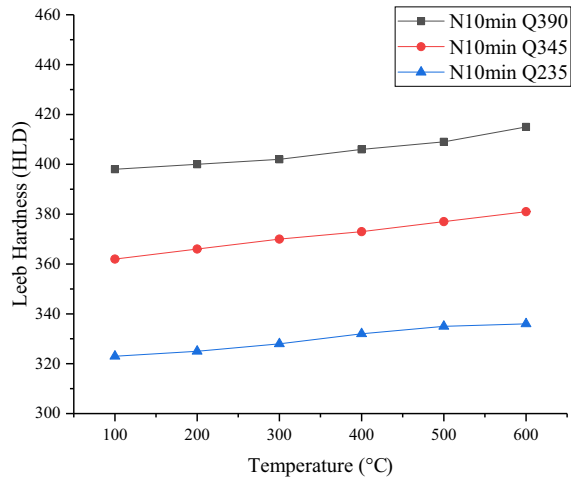

(b) Fire exposure of 10mins

(c) Fire exposure of $15 \mathrm{mins}$

\section{Figure 11. Relation between the Leeb hardness and steel grades under natural cooling.}

In summary, Leeb hardness of the stress state and that of the non-stress state is relatively close, and Leeb hardness of the stress state is slightly higher, which has less influence on the Leeb hardness.

\subsection{Different Leeb Hardness on Steel Flange and Web}

As it is shown in Fig. 12, there is difference of the Leeb hardness at flange and web. So, it is worth further investigating. Leeb hardness of flange and web increases slightly with the increase of fire exposure duration under natural cooling condition. In the case of the same fire temperature and fire exposure duration, Leeb hardness of the flange is about 34 HLD higher than that of the web.

In the case of water cooling, Leeb hardness of flange and web also showed a slight growth trend with the increase of fire exposure duration. In the case of the 


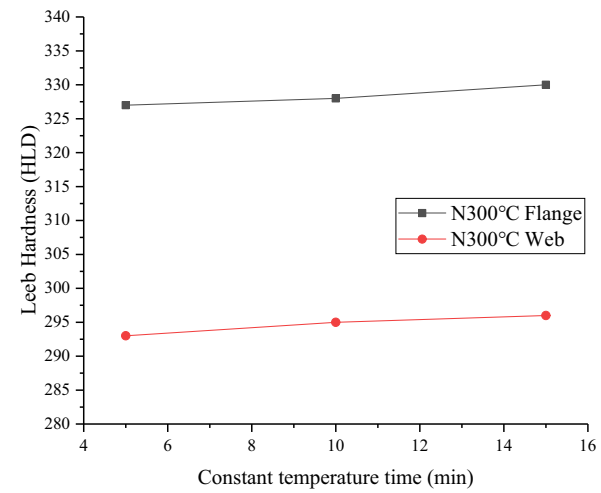

(a) At $300^{\circ} \mathrm{C}$

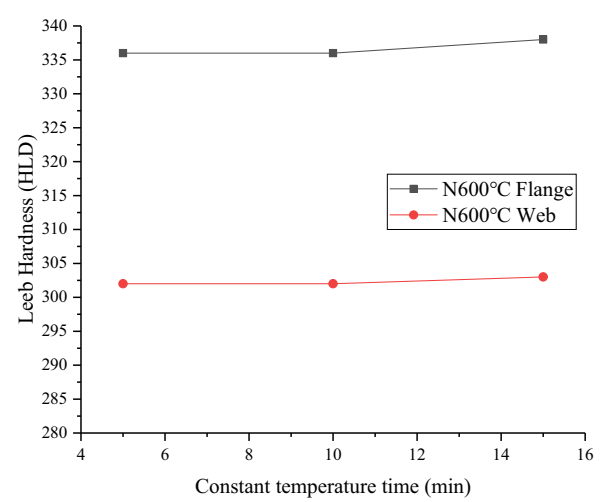

(b) At $600^{\circ} \mathrm{C}$

\section{Figure 12. Different Leeb hardness on steel flange and web under nafural cooling.}

same fire temperature and fire exposure duration, Leeb hardness of the flange is about 36 HLD higher than that of the web.

Regardless of which cooling mode is used, Leeb hardness of the flange is higher than that of the web. The main reasons are as follows: the flange thickness of the specimen is $8 \mathrm{~mm}$, the web thickness is $6 \mathrm{~mm}$, and the weight of a single flange is higher than that of the web. Due to the flange plate is thicker, and is restrained in the middle by the web, the vibration amplitude of the flange is smaller when performing the hardness test, which leads to a higher Leeb hardness than that of the web. The web is usually thinner than the flange, therefore, the amplitude of the vibration induced during the measurement of the Leeb hardness is larger, which causes partial loss of the kinetic energy and the measured value of the Leeb hardness is relatively small. The test results show that the different test positions of the steel are also the main factors affecting the Leeb hardness, and the Leeb hardness of the flange is about 35 HLD higher than that of the web.

\subsection{Effect of Different Test Locations in the Steel Members on Leeb}

\section{Hardness}

As it shown in Figs. 13 and 14, the upper, middle and lower detection positions of the flange and web were tested along the height of the specimens to study the influence of different parts of Leeb hardness. Leeb hardness of the upper and lower parts of the web differs by 1-2 HLD when the specimen is cooled by water at the same fire exposure time. While in the same conditions, Leeb hardness in the middle part of the web is lower, which is 4-5 HLD different from the Leeb hardness in the upper part of the web. When the fire exposure time is the same, Leeb hardness of upper and lower portions of the flange differ by 1-2 HLD, which is very close to each other. While in the same conditions, Leeb hardness in the middle of the flange is lower, and the maximum difference between the hardness values in the upper part of the flange is 7 HLD. The Leeb hardness in the middle of 


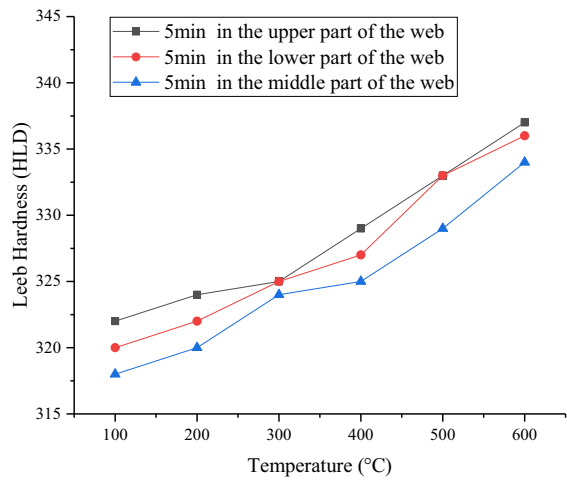

(a) Fire exposure of 5mins

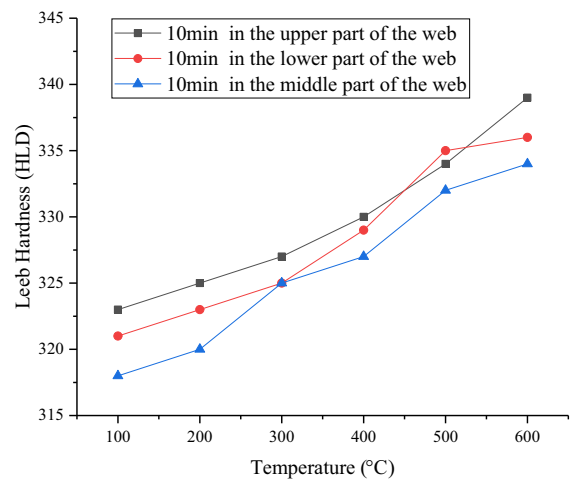

(c) Fire exposure of $15 \mathrm{mins}$

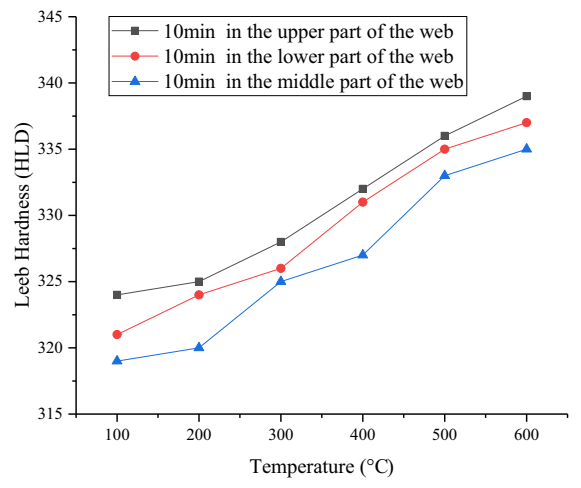

(b) Fire exposure of 10mins

Figure 13. Hardness of different test location of the web.

the flange is 7 HLD different from that in the upper part of the flange when the fire temperature is $100^{\circ} \mathrm{C}$. When the fire temperature is $400^{\circ} \mathrm{C}$, the Leeb hardness of the middle part of the flange is equal to that of the lower part of the flange and is very close to the hardness value at the upper of the flange.

The above observation shows that Leeb hardness of the flange and web of the section steel increase with the increase of the fire temperature. The upper and lower detection points of the flange and the web have a higher Leeb hardness than the middle part of the flange, and the hardness of the middle portion is lower. The reason is that the amplitude of the vibration cause in Leeb hardness test is measured in the middle of the specimen is larger than that of the upper part or the lower part, causing partial loss of the impact kinetic energy, and the measured value of the Leeb hardness is relatively small. 


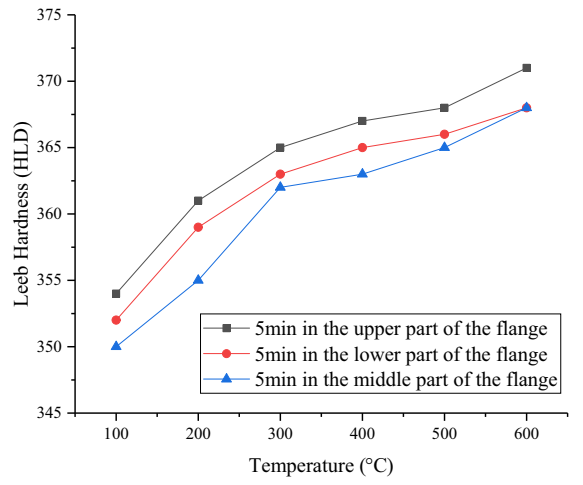

(a) Fire exposure of $5 \mathrm{mins}$

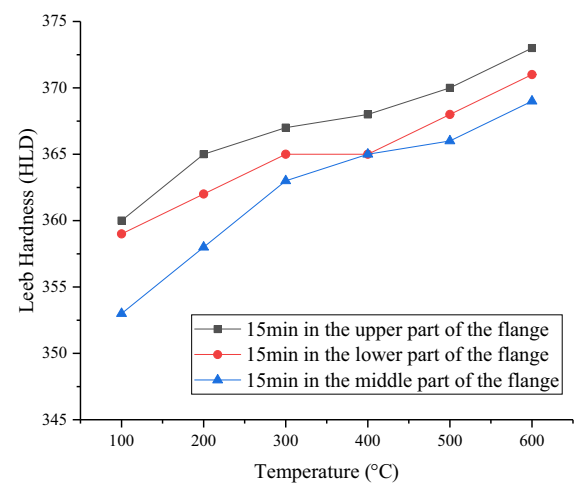

(c) Fire exposure of $15 \mathrm{mins}$

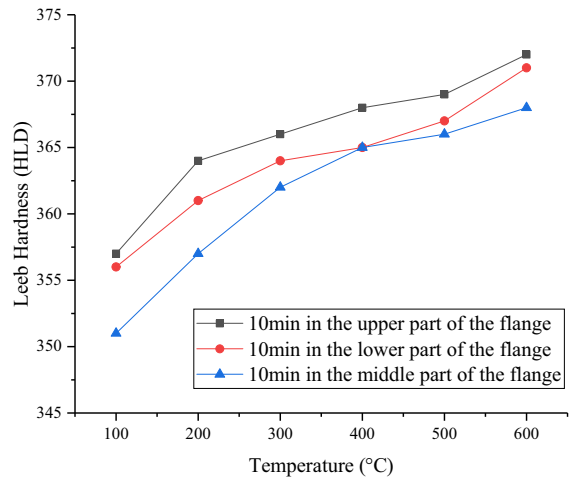

(b) Fire exposure of 10mins

\section{Figure 14. Hardness of different test locations of the flange.}

\subsection{Limitation of Leeb Hardness Method}

From the test results it can be seen that Leeb hardness method is an effective post fire assessment method, however, it also has its limitations. It can only assess the strength of the structural steel member but cannot assess the ductility and deformation reduction due to fire. Other techniques need to be further invested.

\section{Correlation Between the Post Fire Residual Strength of the Steel and Leeb Hardness}

In this section, several regression methods were used to correlate the relation between the Leeb hardness to the residual strength of steel structural members after fire [31-34]. They are: linear regression methods and three non-linear regression methods (quadratic polynomial, exponential function and power function). 


\section{Table 2}

Linear and Nonlinear Regression Analysis Under Ambient Temperature

\begin{tabular}{lccc}
\hline Regression method & $\begin{array}{c}\text { Correlation } \\
\text { coefficient }\end{array}$ & $\begin{array}{c}\text { Mean error } \\
(\%)\end{array}$ & $\begin{array}{c}\text { Standard deviation of } \\
\text { error (\%) }\end{array}$ \\
\hline$\sigma_{\mathrm{b}}=1.929 \times H L D-245.439$ & 0.975 & 2.01 & 2.49 \\
$\sigma_{\mathrm{b}}=0.008 \times H L D^{2}-3.729 \times H L D+807.022$ & 0.987 & 12.17 & 12.82 \\
$\sigma_{\mathrm{b}}=102.574 \times \mathrm{e}^{0.004 \times H L D}$ & 0.985 & 1.46 & 1.96 \\
$\sigma_{\mathrm{b}}=0.055 \times \mathrm{HLD}^{1.531}$ & 0.979 & 1.98 & 2.42 \\
\hline
\end{tabular}

$\sigma_{\mathrm{b}}$ is tensile strength of steel $\left(\mathrm{N} / \mathrm{mm}^{2}\right) ; H L D$ is Leeb hardness

\subsection{Relation Between Tensile Strength and Leeb Hardness Under Ambient Temperature}

Based on the analysis of the test results of 12 specimens at room temperature, the relationship between Leeb hardness and tensile strength of steel was developed. Leeb hardness was measured at upper flange. The tensile strength of coupons from the same position was tested through tensile testing. The correlative equation between Leeb hardness and tensile strength was detailed in Table 2.

As it can be seen from Table 2, the correlation coefficient of polynomial regression equation is the highest, but its mean and standard deviation of errors are larger. The correlation coefficient mean and standard deviation of errors for exponential regression equation are better than linear regression and power function regression equation. Therefore, the exponential regression equation can better reflect the relationship between Leeb hardness and tensile strength at room temperature.

\subsection{Relation Between the Post-fire Tensile Strength and Leeb Hardness at Flange}

The test results show that the Leeb hardness of flange is higher than that of web, so the regression analysis of flange and web were carried out respectively. The Leeb hardness of the upper part of flange with high stability is measured under the condition of $70 \%$ residual capacity after fire. The tensile strength of the corresponding flange obtained in the tensile test. The influence of cooling mode should also be considered in statistical analysis.

4.2.1. Cooling by Water The regression results by different regression methods are depicted in Fig. 15. There are 0.974 of correlation coefficient, $2.23 \%$ of mean error and 2.87 of standard deviation of error in the exponential equation. It shows that the exponential equation is the best to represent the correlation.

4.2.2. Natural Cooling The regression results by different regression methods are depicted in Fig. 16. There are 0.941 of correlation coefficient, $3.26 \%$ of mean 


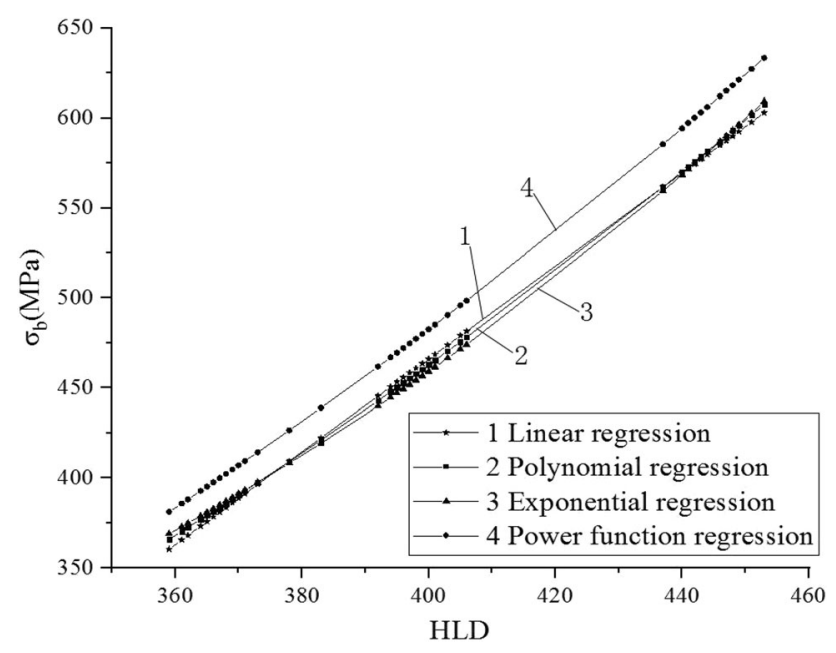

Figure 15. Leeb hardness and tensile strength of flange under water cooling.

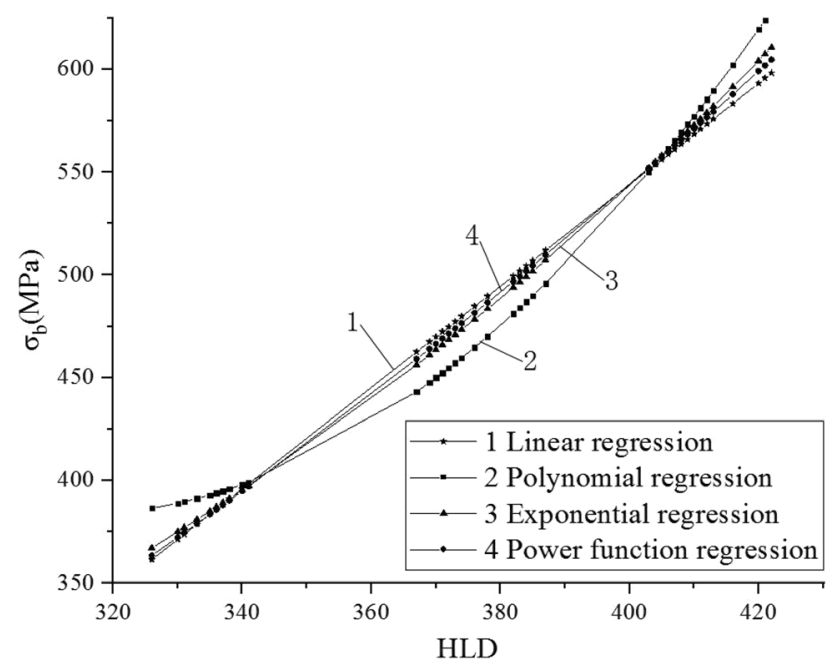

\section{Figure 16. Leeb hardness and tensile strength of flange under natural cooling.}

error and 4.20 of standard deviation of error in the exponential equation. It shows that the exponential equation is the best to represent the correlation.

4.2.3. Comparison of Regression Results to Test Results From the comparison of the regression analysis in Figs. 15 and 16, it can be seen that the exponential regression equation can be used to fit the relationship between Leeb hardness and tensile strength of flange under two cooling modes after fire. Figure 17 shows the 


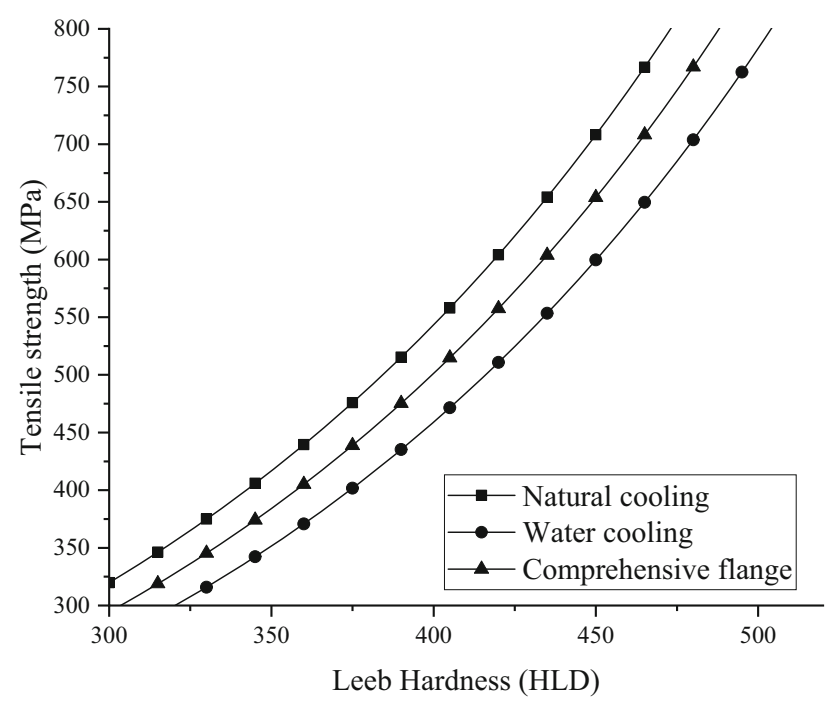

\section{Figure 17. The correlation between the Leeb hardness and the residual tensile strength of flange.}

relationship curve between Leeb hardness and tensile strength of flange using exponential regression under two cooling modes, and the relationship curve between Leeb hardness and tensile strength of flange synthetically obtained by fitting the two curves. The influence of two cooling modes is considered comprehensively in this curve. The relationship between Leeb hardness and tensile strength of composite flange after fire is developed as in Eq. (2).

$$
\sigma_{\mathrm{b}}=59.722 \times \mathrm{e}^{0.005 \times H L D}
$$

Figure 17 shows that the tensile strength of watering cooling is lower than that of natural cooling under the same Leebs hardness; under the same tensile strength, the Leebs hardness of watering cooling is higher than that of natural cooling; and the watering cooling method is equivalent to quenching high-temperature specimens, resulting in the increase of surface hardness.

Table 3 gives the comparison between the calculated values of the formula 2 of Q345 specimen and the measured tensile strength of steel. It can be seen from the table that the maximum error is less than $10 \%$ and the average error is about $5 \%$. It shows that the equation of relationship between Leeb hardness and tensile strength of flange after fire is in good agreement with the measured results.

\subsection{Relation Between the Post-fire Tensile Strength and Leeb Hardness at Web}

Figure 18 shows the relationship curve between Leeb hardness and tensile strength of webs with exponential regression under two cooling modes, and the relation- 
Table 3

The Calculated Strength Using Leeb Hardness and Tested Strength of Flange for 9345 Steel Members

\begin{tabular}{lcccc}
\hline & HLD & Tested tensile strength $(\mathrm{MPa})$ & Calculated tensile strength (MPa) & Errors (\%) \\
\hline$B W_{1}^{5}$ & 392 & 463.69 & 423.99 & 8.6 \\
$B W_{1}^{10}$ & 394 & 475.44 & 428.25 & 9.9 \\
$B W_{1}^{15}$ & 394 & 425.25 & 428.25 & 0.7 \\
$B W_{2}^{5}$ & 394 & 454.38 & 428.25 & 5.8 \\
$B W_{2}^{10}$ & 395 & 427.63 & 430.39 & 0.6 \\
$B W_{2}^{15}$ & 396 & 443.06 & 432.55 & 2.4 \\
$B W_{3}^{5}$ & 397 & 452.00 & 434.72 & 3.8 \\
$B W_{3}^{10}$ & 397 & 476.81 & 434.72 & 8.8 \\
$B W_{3}^{15}$ & 398 & 456.00 & 436.90 & 4.2 \\
$B W_{4}^{5}$ & 399 & 438.31 & 439.09 & 0.2 \\
$B W_{4}^{10}$ & 400 & 457.13 & 441.29 & 3.5 \\
$B W_{4}^{15}$ & 401 & 462.81 & 443.50 & 4.2 \\
$B W_{5}^{5}$ & 403 & 464.06 & 447.96 & 3.5 \\
$B W_{5}^{10}$ & 403 & 476.56 & 447.96 & 6.0 \\
$B W_{5}^{15}$ & 403 & 483.31 & 447.96 & 7.3 \\
$B W_{6}^{5}$ & 405 & 474.31 & 452.46 & 4.6 \\
$B W_{6}^{10}$ & 405 & 490.94 & 452.46 & 7.8 \\
$B W_{6}^{15}$ & 406 & 476.56 & 454.73 & 4.6 \\
\hline
\end{tabular}

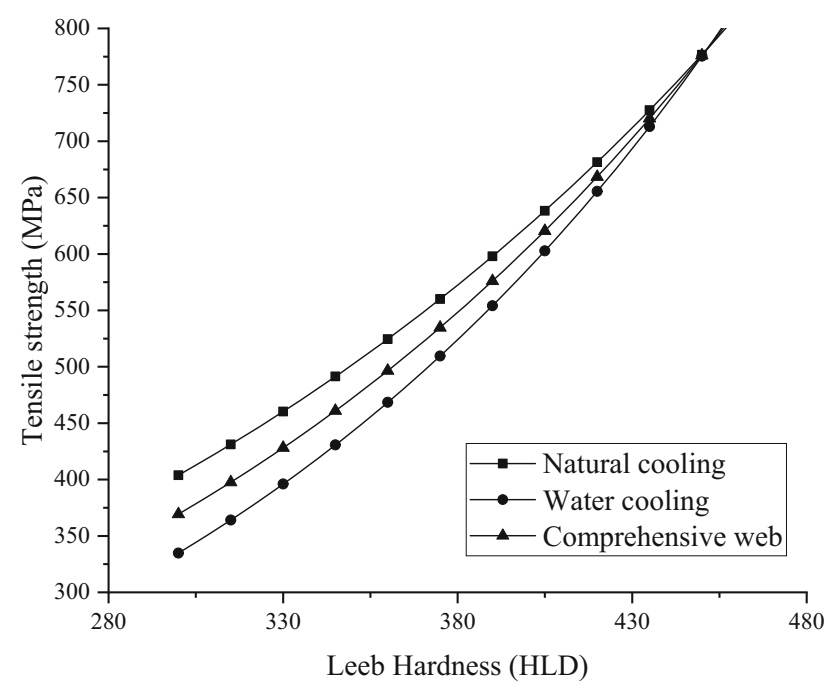

Figure 18. The correlation between the Leeb hardness and the residual tensile strength of web. 


\section{Table 6}

The Calculated Strength Using Leeb Hardness and Tested Strength of Web for Q390 Steel Members

\begin{tabular}{lcccc}
\hline & HLD & Tested tensile strength (MPa) & Calculated tensile strength (MPa) & Errors (\%) \\
\hline$C N_{1}^{5}$ & 371 & 551.67 & 571.37 & 3.6 \\
$C N_{1}^{10}$ & 372 & 544.75 & 574.24 & 5.4 \\
$C N_{1}^{15}$ & 373 & 574.50 & 577.12 & 0.5 \\
$C N_{2}^{5}$ & 373 & 557.25 & 577.12 & 3.6 \\
$C N_{2}^{10}$ & 374 & 568.33 & 580.01 & 2.1 \\
$C N_{2}^{15}$ & 374 & 555.50 & 580.01 & 4.4 \\
$C N_{5}^{5}$ & 376 & 549.42 & 585.84 & 6.6 \\
$C N_{3}^{10}$ & 376 & 564.75 & 585.84 & 3.7 \\
$C N_{3}^{15}$ & 376 & 551.67 & 585.84 & 6.2 \\
$C N_{4}^{5}$ & 378 & 585.08 & 591.73 & 1.1 \\
$C N_{4}^{10}$ & 379 & 559.33 & 594.69 & 6.3 \\
$C N_{4}^{15}$ & 379 & 570.83 & 594.69 & 4.2 \\
$C N_{5}^{5}$ & 380 & 562.17 & 597.67 & 6.3 \\
$C N_{5}^{10}$ & 381 & 581.75 & 600.67 & 3.3 \\
$C N_{5}^{15}$ & 381 & 588.08 & 600.67 & 2.1 \\
$C N_{6}^{5}$ & 382 & 578.58 & 603.68 & 4.3 \\
$C N_{6}^{10}$ & 383 & 572.25 & 606.70 & 6.0 \\
$C N_{6}^{15}$ & 384 & 575.83 & 609.75 & 5.9 \\
\hline
\end{tabular}

ship curve between Leeb hardness and tensile strength of webs obtained by fitting the two curves. The influence of two cooling modes is considered comprehensively in this curve. The relationship between Leeb hardness and tensile strength of composite web after fire is developed in Eq. (3).

$$
\sigma_{\mathrm{b}}=82.393 \times \mathrm{e}^{0.005 \times H L D}
$$

Figure 18 shows that the relationship between Leeb hardness and tensile strength of web is basically the same as that between Leeb hardness and tensile strength of flange, but with the increase of Leeb hardness or tensile strength, the difference between flange and web becomes smaller and smaller.

Formula (3) is developed based on 3 grades of steel specimens Q345, Q345 and Q390. Table 6 gives a comparison between the calculated value of web using formula (3) and the measured tensile strength of Q390 steel specimens. It can be seen from the table that the maximum error is $6.6 \%$ and the average error is about $5 \%$. It shows that the equation of relationship between Leeb hardness and tensile strength of web after fire is in good agreement with the measured results. Table 6 is not to validate the equation but to show the error range for each equation. 


\section{Conclusion}

In this paper, a new nondestructive Post-fire Damage Assessment method using Leeb hardness test was first time developed. 120 steel sections were first tested in fire. The post fire Leeb Hardness tests were conducted afterwards. The influence of relevant factors on the Leeb hardness of structural steel members after fire was first time studied. The correlation function between Leeb hardness and the residual tensile strength of the steel members after fire has been developed. The following conclusions can be drawn:

(1) The new nondestructive Post-fire Damage Assessment method developed in this paper provides a simple, fast and accurate way for the residual strength assessment of the structural steel after fire.

(2) The correlation function between Leeb hardness and the residual tensile strength of the steel members after fire is developed; it can accurately predict the residual strength of steel members after fire.

(3) When the fire exposure time is the same, Leeb hardness of members using water cooling method exhibit higher value than that of members using the natural cooling method are with an average increase of about 35 HLD, so the cooling mode has great influence on the Leeb hardness.

(4) The Leeb hardness increases with the increase of the fire temperature. When the fire temperature rises from $100^{\circ} \mathrm{C}$ to $600^{\circ} \mathrm{C}$, Leeb hardness increases by 12 HLD on average; with the increase of fire exposure time, the Leeb hardness shows a slight growth rate. The fire exposure time was from $5 \mathrm{~min}$ to $15 \mathrm{~min}$, the corresponding increase of the Leeb hardness was around 3 HLD.

(5) The hardness of the steel increases greatly with the increase of steel strength grade in the same conditions of cooling mode and fire exposure time, and it increases substantially linearly. The strength grade of steel has the greatest influence on the hardness of the steel.

\section{Open Access}

This article is licensed under a Creative Commons Attribution 4.0 International License, which permits use, sharing, adaptation, distribution and reproduction in any medium or format, as long as you give appropriate credit to the original author(s) and the source, provide a link to the Creative Commons licence, and indicate if changes were made. The images or other third party material in this article are included in the article's Creative Commons licence, unless indicated otherwise in a credit line to the material. If material is not included in the article's Creative Commons licence and your intended use is not permitted by statutory regulation or exceeds the permitted use, you will need to obtain permission directly from the copyright holder. To view a copy of this licence, visit http://creat ivecommons.org/licenses/by/4.0/. 


\section{References}

1. Maraveas C, Fasoulakis Z, Tsavdaridis KD (2017) Assessment and reinstatement of steel structures. J Struct Fire Eng 8(2):181-201

2. Smith CI, Kirby BR, Lapwood DG, Cole KJ, Cunningham AP, Preston RR (1981) The reinstatement of fire damaged steel framed structures. Fire Saf J 4(1):21-26

3. Tide RHR (1998) Integrity of structural steel after exposure to fire. Eng J 35(1):26-38

4. Wei L (2013) The research on detection error in the Leeb hardness testing of cast iron and nitrided parts. Master thesis, Hunan University

5. Zhou Y, Zheng X (2009) Macroscopic and microscopic mechanical properties of materials. Higher Education Press, Beijing

6. Leeb D (1979) Dynamic hardness testing of metallic materials. NDT Int 12(6):274-278

7. Kompatscher M (2005) Dynamic hardness measurements. MAPAN J Metrol Soc India 20(1):25-36

8. O'Neill H (1967) Hardness of metals and its measurement. Chapman \& Hall Ltd, London

9. Williams SR (1942) Hardness and hardness measurements. American Society for Metals, Cleveland

10. ISO/TR 10108 (1989) Steel - conversion of hardness values to tensile strength values

11. Krzemien K, Hager I (2015) Post-fire assessment of mechanical properties of concrete with the use of the impact-echo method. Constr Build Mater 96:155-163

12. Hwang E, Kim G, Choe G, Yoon M, Gucunski N, Nam J (2018) Evaluation of concrete degradation depending on heating conditions by ultrasonic pulse velocity. Constr Build Mater 171:511-520

13. British Standard (BS EN 1991-1-2:2002) (2002) Eurocode 1: actions on structures-part 1-2: general actions - actions on structures exposed to fire. European Committee for Standardization

14. ASTM Designation (1998) Standard test methods for fire tests of building construction and material. ASTM Committee, E (5)

15. International Standard ISO834 (1975) Fire-resistance tests-elements of building construction

16. Babrauskas V, Williamson RB (1978) The historical basis of fire resistance testing-part I. Fire Technol 14(3):184-194

17. Fairbairn DR (1984) European recommendations for the fire safety of steel structures: calculation of the fire resistance of load bearing elements and structural assemblies exposed to the standard fire. Fire Saf J 7(2):204

18. Ou M (2007) Research and application of mechanical properties of steel structure in fire conditions. Master thesis, Hunan University

19. Mu Q (2011) A time-variant reliability analysis on structural members under fire. $\mathrm{PhD}$ thesis, Harbin Engineering University

20. Ozyurt E, Wang YC (2015) Effects of truss behaviour on critical temperatures of welded steel tubular truss members exposed to uniform fire. Eng Struct 88:225-240

21. Liu M, Zhao J, Jin M (2009) An experimental study of the mechanical behavior of steel planar tubular trusses in a fire. J Constr Steel Res 66(4):504-511

22. Yu W, Zhao J, Luo H (2011) Experimental study on mechanical behavior of an impacted steel tubular T-joint in fire. J Constr Steel Res 67(9):1376-1380

23. Wang W, Liu T, Liu J (2015) Experimental study on post-fire mechanical properties of high strength Q460 steel. J Constr Steel Res 114:100-109

24. Wang W, Liu B, Kodur V (2013) Effect of temperature on strength and elastic modulus of high-strength steel. J Mater Civ Eng 25(2):174-182 
25. Gardner L, Insausti A, Ng KT, Ashraf M (2009) Elevated temperature material properties of stainless steel alloys. J Constr Steel Res 66(5):634-647

26. Duan X, Yan X, Zhou Y, Tao L (2003) Experimental study on conversion steel Leebhardness and tensile strength. Build Sci 19(3):48-50

27. Chinese Standard "Metallic materials - Leeb hardness test-part 4: tables of hardness values conversation" GB/T 17394.4, 2014

28. State Standard of the People's Republic of China GB/T 1172-1999, Conversion of hardness and strength for ferrous metal, State Bureau of Quality and Technical Supervision, 1999

29. Wang WG (2016) Study on determination method of steel strength after fire. Master thesis, Jilin Jianzhu University

30. Maraveas C, Fasoulakis Z, Tsavdaridis KD (2017) Mechanical properties of high strength and very high strength steel at elevated temperatures and after cooling down. Fire Sci Rev 6:3

31. Mirmomeni M, Heidarpour A, Zhao X-L, Hutchinson CR, Packer JA, Wu C (2015) Mechanical properties of partially damaged structural steel induced by high strain rate loading at elevated temperatures - an experimental investigation. Int J Impact Eng 76(2): $178-188$

32. Sadiq H, Wong MB, Tashan J, Al-Mahaidi R, Zhao XL (2013) Determination of steel emissivity for the temperature prediction of structural steel members in fire. J Mater Civ Eng 25(2):167-173

33. Chiew SP, Zhao MS, Lee CK (2014) Mechanical properties of heat-treated high strength steel under fire/post-fire conditions. J Constr Steel Res 98(7):12-19

34. Rodrigues JPC, Neves IC, Valente JC (2000) Experimental research on the critical temperature of compressed steel elements with restrained thermal elongation. Fire Saf $\mathbf{J}$ 35(2):77-98

Publisher's Note Springer Nature remains neutral with regard to jurisdictional claims in published maps and institutional affiliations. 